\title{
Subjective and Objective Assessment of Taste and Smell Sensation in Advanced Cancer
}

\author{
Niamh McGettigan \\ Trinity College Dublin, Ireland \\ Pauline Uí Dhuibhir \\ University College Dublin \\ Michelle Barrett \\ Trinity College Dublin, Ireland
}

See next page for additional authors

Follow this and additional works at: https://arrow.tudublin.ie/scschbioart

Part of the Biology Commons, and the Oncology Commons

\section{Recommended Citation}

McGettigan, N., Dhuibhir, P. U., Barrett, M., Sui, J., Balding, L., Higgins, S., O’Leary, N., Kennedy, A., \& Walsh, D. (2019). Subjective and Objective Assessment of Taste and Smell Sensation in Advanced Cancer. American Journal of Hospice and Palliative Medicine ${ }^{8}, 36(8), 688-696$. DOI: 10.1177/

1049909119832836

This Article is brought to you for free and open access by the School of Biological Sciences at ARROW@TU Dublin. It has been accepted for inclusion in Articles by an authorized administrator of ARROW@TU Dublin. For more information, please contact arrow.admin@tudublin.ie, aisling.coyne@tudublin.ie,gerard.connolly@tudublin.ie.

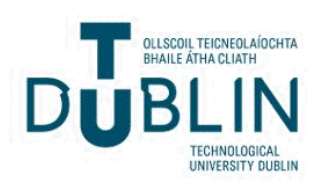




\section{Authors}

Niamh McGettigan, Pauline Uí Dhuibhir, Michelle Barrett, Jessica Sui, Lucy Balding, Stephen Higgins, Norma O'Leary, Aileen Kennedy, and Declan Walsh 


\title{
Subjective and Objective Assessment of Taste and Smell Sensation in Advanced Cancer
}

American Journal of Hospice \& Palliative Medicine ${ }^{\circledR}$ 2019, Vol. 36(8) 688-696 (C) The Author(s) 2019 Article reuse guidelines: sagepub.com/journals-permissions DOI: 10.1 I77/I049909। I9832836 journals.sagepub.com/home/ajh

(9SAGE

\author{
Niamh McGettigan, BSc ${ }^{1,2}$, Pauline Uí Dhuibhir, $\mathrm{MSc}^{3,4}$, \\ Michelle Barrett, $\mathrm{MSc}^{3,5}$, Jessica Sui, MSc, MRCPI ${ }^{1,3}$, \\ Lucy Balding, MSc, MRCPI ${ }^{3,6}$, Stephen Higgins, MB, BCh, BAO, MRCPI ${ }^{3,7}$, \\ Norma O'Leary, MD, MB, BCh, BAO, BMedSc, MRCPI, \\ Aileen Kennedy, $\mathrm{PhD}^{2}$, and Declan Walsh, MB, BCh, BAO, MSc ${ }^{1,3,8}$
}

\begin{abstract}
Context: Taste and smell abnormalities (TSA) occur throughout the cancer trajectory regardless of cancer primary site and contribute to cancer-associated malnutrition. TSA etiology is poorly understood. Tumor-related inflammation is a possible cause. Objective: This study examined the prevalence, characteristics, and severity of TSA in advanced cancer and explored the relationship between TSA and nutritional status. No previous study combined subjective and objective measures for both taste and smell assessment in this population. Method: Consecutive advanced cancer hospice patients were recruited. A modified version of the "Taste and Smell Survey" assessed subjective TSA. Validated taste strips and "Sniffin' Sticks" were the objective measures. The abridged patient-generated subjective global assessment evaluated nutritional status. Results: A 93\% prevalence of TSA in 30 patients with advanced cancer was identified. When subjective and objective evaluations were combined, 28 had taste abnormalities, 24 smell abnormalities, and 24 both. Taste changes included "persistent bad taste" $(n=18)$ and changes in how basic tastes were perceived. Half reported smell was not "as strong" as prediagnosis, while more than half $(n=16)$ had an objective smell abnormality. Most (97\%) were at risk of malnutrition. Fatigue, dry mouth, early satiety, and anorexia were common nutrition-impact symptoms. No statistically significant relationship was found between TSA and malnutrition scores. Conclusions: TSA were highly prevalent. Subjective taste and smell changes did not always accord with objective TSA, suggesting both assessments are valuable. TSA characteristics varied, and particular foods tasted and smelled different and were not enjoyed as before. TSA are common, high-impact problems in advanced cancer.
\end{abstract}

\section{Keywords}

assessment, cancer, nutrition, smell, symptoms, taste

\section{Introduction}

Malnutrition is a complex condition, prevalent in up to $90 \%$ of persons with advanced cancer. ${ }^{1}$ Nutritional symptoms are common and contribute to malnutrition risk. Taste and smell abnormalities (TSA) can impact food enjoyment and intake, nutritional status, and quality of life (QoL). ${ }^{1,2}$ The prevalence of TSA ranges from $60 \%$ to $86 \%$ in advanced cancer. ${ }^{3}$ Disturbances in taste and smell may occur alone, but more frequently co-occur with other nutrition impact symptoms (NIS) like dry mouth, early satiety, fatigue, nausea or pain. ${ }^{4,5}$ When such symptoms co-occur, the cause and relative impact of individual symptoms can be difficult to determine.

Although TSA seem common, the absence of a gold standard assessment means evaluation is uncommon in routine clinical practice. Inconsistent taste and smell terminology contribute to this. The words "flavor" and "taste," for example, are

\footnotetext{
' School of Medicine, Trinity College Dublin, Dublin, Ireland

${ }^{2}$ School of Biological Sciences, Dublin Institute of Technology, Kevin St., Dublin, Ireland

${ }^{3}$ Academic Department of Palliative Medicine, Our Lady's Hospice \& Care Services, Dublin, Ireland

${ }^{4}$ School of Nursing, Midwifery \& Health Science, University College Dublin, Dublin, Ireland

${ }^{5}$ School of Nursing \& Midwifery, Trinity College Dublin, Dublin, Ireland

${ }^{6}$ St James' Hospital, Dublin, Ireland

${ }^{7}$ Tallaght University Hospital, Dublin, Ireland

${ }^{8}$ School of Medicine \& Medical Science, University College Dublin, Dublin, Ireland
}

\section{Corresponding Author:}

Declan Walsh, MB, BCh, BAO, MSc, Department of Supportive Oncology, Levine Cancer Institute, 7I I Morehead St, Charlotte, NC 28202, USA.

Email: declan.walsh@atriumhealth.org 
interchangeable in everyday speech. Taste is just one aspect of flavor (which also incorporates consistency, smell, and temperature). ${ }^{6}$ Some small studies suggest a relationship between smell and taste. ${ }^{7}$ However, a large study concluded that smell had little influence on taste. ${ }^{8}$ Subjective and objective measures capture TSA prevalence, characteristics and severity. ${ }^{1,9-11}$ Subjective measures provide information on individual chemosensory experiences. Objective measures determine the ability to recognize tastes and smells.

Possible mechanisms are poorly understood and understudied, ${ }^{6,12,13}$ but inflammation is identified as a possible cause. ${ }^{14}$ Research has largely focused on head and neck cancer TSA as a consequence of chemotherapy and/or radiotherapy. TSA are reported in treatment-naïve and patients with advanced cancer,

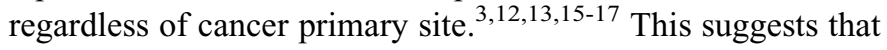
the tumor itself may play a role in TSA etiology.

Increased understanding of the extent and impact of TSA in advanced disease will progress the development of suitable screening/assessment strategies and clinical interventions. This study aimed to examine the prevalence, characteristics, and severity of TSA in advanced cancer by both subjective and objective assessments. We hoped to evaluate the clinical utility of available assessment methods. We also explored the relationship between TSA and nutritional status.

\section{Methods}

A prospective cross-sectional observational study was conducted in an in-patient palliative care unit. Consecutive admissions with an advanced cancer who had a life expectancy $>7$ days and an Eastern Cooperative Oncology Group $(\mathrm{ECOG})^{18}$ performance status $\leq 3$, were identified at multidisciplinary team meetings and invited to participate. Those with a diagnosis of dementia, current oral candidiasis, Nausea, vomiting or considered too unwell were excluded. Recruitment occurred over 7 consecutive weeks. The study was approved by the Medical Ethics Committee, St Vincent's University Hospital, Dublin. Participants provided written informed consent after verbal and written explanation. Participant characteristics were obtained from medical health-care records. Observational measures were conducted at the bedside by a student dietitian $\left(\mathrm{NM}^{\mathrm{c}} \mathrm{G}\right)$ in 30 to 40 minute interactions. Participants were advised not to drink, eat, or smoke for 1 hour beforehand.

\section{Taste and Smell Survey}

A modified version of the "Taste and Smell Survey" (TSS; Figure 1$)^{19}$ was used to explore the prevalence, characteristics and severity of taste changes (TC) and smell changes (SC) since becoming ill. Four medication questions in the original version were omitted; 12 items remained ( 7 for taste; 5 for smell). Although not validated, it has been used before in the oncology setting, ${ }^{11,20-22}$ including advanced cancer. ${ }^{1}$

The TSS responses generated a chemosensory complaint score. One point was awarded for each reported complaint. A further point was awarded when it was "mild/moderate" or "rarely/sometimes" and a further 2 if "severe/incapacitating" or "often/always." Taste changes yielded a potential score of 0 to 10 ( $0=$ no changes; $10=$ multiple severe changes $)$. Smell changes ranged from 0 to $5(0=$ no changes; $5=$ multiple, severe changes). A combined chemosensory complaint score of 0 to 15 was also calculated. Two unscored, open questions (Q10, 12) allowed participants describe how TSA impacted QoL. Question 6 was also unscored.

\section{Objective Assessment}

Objective measures determined the prevalence and characteristics of impaired taste (ITP) and smell perception (ISP). Neither measured severity.

The ability to recognize and identify 4 basic taste modalities (bitter, salty, sour, and sweet) was assessed by validated taste strips (Burghart Messtechnik GmbH, Wedel, Germany). ${ }^{23}$ Umami is not widely known in Ireland and was not assessed. The taste strips were applied to the tongue for whole-mouth testing. Strips were presented randomly, except bitter which was always done last (due to lasting taste). Strips were placed onto the centre of the tongue and the mouth then closed. After a timed 10 seconds (timed by iPhone 5, Apple, San Francisco, California), the strip was removed and the participant asked to identify the taste. After each strip the participant swallowed 10 to $20 \mathrm{ml}$ of still cold water (Tesco, Perthshire, United Kingdom) to cleanse the palate. The researcher waited 30 seconds before the next taste strip. Each correct answer got a score of one (with a possible maximum score of 4). Each incorrect answer indicated a taste abnormality (TA). When a taste was not identified, participants were asked to guess.

The "Sniffin' Sticks" (Burghart Messtechnik GmbH, Wedel, Germany) odor identification test assessed smell. ${ }^{24,25}$ Twelve odor-filled pens (numbered 1-12) were used in numerical sequence. Each was uncovered and held $2 \mathrm{~cm}$ from the tip of the nose for four timed seconds (iPhone 5, Apple, San Francisco, California). When each pen was offered, a card with 4 odor pictures/descriptors (eg, glue, grass, leather, smoke) was also presented. The participant chose the descriptor that identified the odor. Similar to taste, participants were encouraged to guess if unsure. A timed one-minute pause was observed between each pen. A score of one was given for each correct answer (maximum possible score was 12). Scores were then categorized (as per instruction manual): Normal smell: 10 to 12; Smell Abnormality (SA): hyposmia (reduced): 6 to 9; anosmic (absence): $\leq 5$.

\section{Nutritional Screening}

An abridged version of the original Patient-Generated Subjective Global Assessment ${ }^{26}$ (abPG-SGA) was used to assess nutritional status (Figure 2). This is a validated screening tool in oncology. ${ }^{27}$ It evaluated 4 areas: (1) self-reported height, weight, and weight history; (2) recent dietary intake; (3) NIS 
The purpose of this survey is to see how people experience taste and smell changes. Please answer the following questions as best you can I. Have you noticed any changes in your sense of taste?

If yes, please describe:

2. Have you noticed any changes in your sense of smell?

If yes, please describe:

3. Have you ever noticed that a food tastes different than it used to?

If yes, please describe:

4. Have you ever noticed that a food smells different than it used to?

If yes, please describe:

5. I have a persistent bad taste in my mouth

I. never

2. rarely

3. sometimes

4. often

5. always

6. The persistent taste is
I. salty
2. sweet (like sugar)
3. sour (like lemon or vinegar)
4. bitter (like black coffee or tonic water)
5. other (specify)

7. Comparing my sense of taste now to the way it was before I became ill

- Salt tastes

I. stronger

2. as strong

3. weaker

4. I cannot taste it at all

- Sweet (sugar) tastes

I. Stronger

2. as strong

3. weaker

4. I cannot taste it at all

- Sour (lemon or vinegar) tastes

I. Stronger

2. as strong

3. weaker

4. I cannot taste it at all

- Bitter (black coffee or tonic water) tastes

I. Stronger

2. as strong

3. weaker

4. I cannot taste it at all

8. Comparing my sense of smell now to the way it was before I became ill, odors are
I. Stronger
2. as strong
3. weaker
4. I cannot smell at all

9. Over the past 3 months, I would rate my abnormal sense of taste as: (circle BEST answer)

I. insignificant

2. mild

3. moderate

4. severe

5. incapacitating

10. How has your abnormal sense of taste affected your quality of life?

II. Over the past 3 months, I would rate my abnormal sense of smell as:(circle BEST answer)

I. insignificant

2. mild

3. moderate

4. severe

5. incapacitating

12. How has your abnormal sense of smell affected your quality of life?

Figure I. Modified taste and smell survey (from Heald et al 1998). 


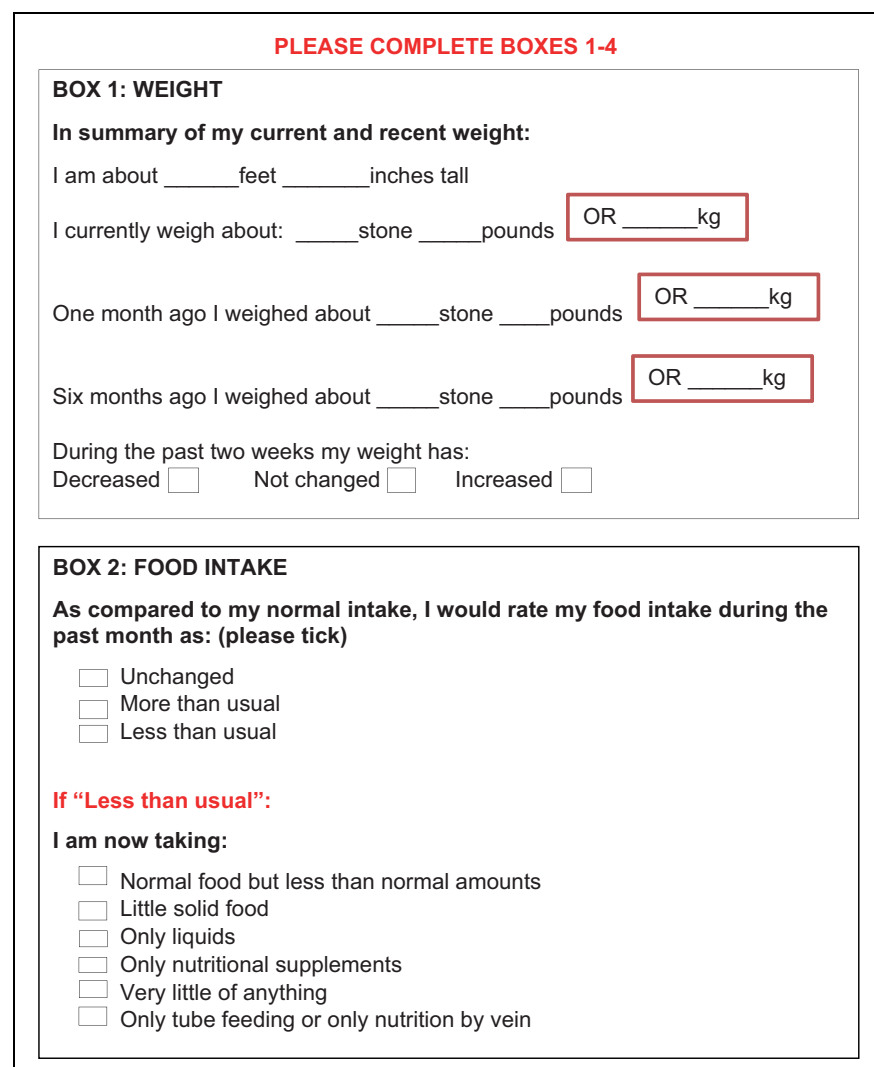

BOX 3: SYMPTOMS
I have had the following problems that have kept me from eating enough during
the past two weeks (tick all that apply):
$\square$ No problems eating
$\square$ No appetite, just did not feel like eating
$\square$ Nausea
$\square$ Vomiting
$\square$ Constipation
$\square$ Diarrhoea
$\square$ Mouth sores
$\square$ Dry mouth
$\square$ Things taste funny or have no taste
$\square$ Smells bother me
$\square$ Problems swallowing
$\square$ Feel full quickly
$\square$ Fatigue
Pain: where_
Other*

BOX 4: ACTIVITIES AND FUNCTION

Over the past month, I would generally rate my activity as: (please circle)

Normal with no limitations

Not my normal self, but able to be up and about with fairly normal activities Not feeling up to most things, but in bed or chair less than half the day

Able to do little activity and spend most of the day in bed or chair

$\checkmark$ Pretty much bedridden, rarely out of bed

Figure 2. Abridged patient-generated subjective global assessment (abPG-SGA; Ottery 1996; Gabrielson et al. 2013).

including taste and smell; (4) current activity and function. Scores ranged from 0 to 36 ; $\geq 6$ has high sensitivity and specificity for malnutrition risk. ${ }^{27}$

\section{Data Analysis}

Data analysis was performed using SPSS $^{\circledR}$ version 24 (IBM Corporation, New York). Descriptive statistics were reported as means $( \pm \mathrm{SD})$, medians (range) and percentages. All results were rounded to the nearest whole number. Binary logistic regression investigated the relationship between age and TSA. Cross-tabulation and a $\chi^{2}$ statistical test examined the relationship between categorical variables. Linear regression evaluated the relationship between TSA and abPG-SGA scores. Statistical significance was set at $P$ $<.05$ (2-sided).

\section{Results}

\section{Patient Characteristics}

Fifty-two consecutive advanced cancer admissions were identified. Of those, 30 participated and completed the study. Reasons for nonparticipation were; changed clinical status $(\mathrm{n}=$ $10)$, declined $(\mathrm{n}=8)$, died $(\mathrm{n}=2)$, and discharged $(\mathrm{n}=2)$. Mean age was 68 years $(\mathrm{SD}= \pm 12)$. Cancer types were solid tumors (29/30) and multiple myeloma (1/30). Baseline study population characteristics are in Table 1.

\section{Taste and Smell Abnormality Prevalence}

The prevalence varied by assessment type (Figure 3). Subjective prevalence was higher by TSS (taste: $\mathrm{n}=28$; smell $\mathrm{n}=$ 21) than by abPG-SGA (a single question each for taste and smell; taste: $\mathrm{n}=17$; smell: $\mathrm{n}=10$ ). Of those with subjective TC $(\mathrm{n}=28), 12$ had no objective ITP. Everyone with objective ITP $(\mathrm{n}=16)$ also reported subjective TC on TSS. Eight with subjective SC had no objective ISP. Three hyposmic participants reported no subjective SC.

Multiple TSA were reported by some, others a single abnormality. TC were more common than SC. Seven with subjective TC reported no subjective SC. Everyone with subjective $\mathrm{SC}(\mathrm{n}=21)$ also had subjective TC. In objective tests, prevalence was similar for TA and SA: 10 had both and the rest either TA $(n=6)$ or SA $(n=6)$ alone. Binary logistic regression showed no statistically significant relationship between gender $(P=.338)$, treatment type $(P=.626)$ or smoking status $(P=.073)$ and TSA.

\section{Taste and Smell Abnormality Characteristics}

The characteristics of TSA are in Figure 4. The single most common subjective complaint was a persistent bad taste $(\mathrm{n}=$ 18). This was described variously including "bitter," "coppery," "dirty," "metallic," "poison," "salty," "sickening," and "like something gone off." In half, the bad taste occurred "often" $(\mathrm{n}=5)$ or "always" $(\mathrm{n}=4)$.

Taste changes were reported for all taste modalities. Over half $(\mathrm{n}=16)$ said specific foods tasted different since becoming ill and were not as enjoyable. Some reported food "tastes bland" $(\mathrm{n}=6)$ or "has no taste at all" $(\mathrm{n}=5)$. Words like 
Table I. Study Demographic Characteristics.

\begin{tabular}{|c|c|}
\hline Characteristic & Study Population $(\mathrm{n}=30)$ \\
\hline \multicolumn{2}{|l|}{ Gender } \\
\hline Male & 9 \\
\hline Female & 21 \\
\hline \multicolumn{2}{|l|}{ Age } \\
\hline$<65$ years & 13 \\
\hline$\geq 65$ years & 17 \\
\hline \multicolumn{2}{|l|}{ Primary diagnosis } \\
\hline Lung & 9 \\
\hline Breast & 7 \\
\hline Gastrointestinal & 4 \\
\hline Prostate & 3 \\
\hline Gynaecological & 3 \\
\hline Other & 4 \\
\hline \multicolumn{2}{|l|}{ Previous cancer treatment } \\
\hline Chemotherapy & 18 \\
\hline Radiotherapy & 18 \\
\hline Surgery & 9 \\
\hline Hormones & 5 \\
\hline Immunotherapy & 4 \\
\hline \multicolumn{2}{|l|}{ Current cancer treatment } \\
\hline Chemotherapy & 3 \\
\hline Radiotherapy & 1 \\
\hline \multicolumn{2}{|l|}{ Surgery } \\
\hline Hormones & 3 \\
\hline Immunotherapy & I \\
\hline \multicolumn{2}{|l|}{ BMl category ${ }^{28}$} \\
\hline Underweight $\left(<18.5 \mathrm{~kg} / \mathrm{m}^{2}\right)$ & 7 \\
\hline Normal $\left(18.5-24.9 \mathrm{~kg} / \mathrm{m}^{2}\right)$ & 11 \\
\hline Overweight $\left(25-29.9 \mathrm{~kg} / \mathrm{m}^{2}\right)$ & 6 \\
\hline Obese $\left(\geq 30 \mathrm{~kg} / \mathrm{m}^{2}\right)$ & 3 \\
\hline Not available & 3 \\
\hline \multicolumn{2}{|l|}{ Smoking status } \\
\hline Previous & 9 \\
\hline Current & 9 \\
\hline Non-smoker & 12 \\
\hline \multicolumn{2}{|l|}{$\mathrm{ECOG}^{16}$ score } \\
\hline $0-1$ & 0 \\
\hline 2 & 9 \\
\hline 3 & 21 \\
\hline
\end{tabular}

Abbreviations: BMI, body mass index; ECOG, Eastern Cooperative Oncology Group.

"horrible," "undesirable," and "disgusting" were used to describe the loss of appeal of food. Eating was "not the same" as before $(n=2)$ and TSA had turned some off eating $(n=4)$.

Subjective TSS assessment captured both increased and decreased taste perception whereas objective measures could only detect ITP. Salty $(\mathrm{n}=15,50 \%)$ and sweet $(\mathrm{n}=14,47 \%)$ tastes had most often changed. "Salty" was predominantly weaker/could not taste and "sweet" mostly stronger. Across the 4 tastes, there were 22 individual complaints of stronger tastes and 18 weaker/could not taste.

In objective tests over half $(n=16 / 30)$ could not correctly identify all 4 taste modalities. Two did not detect any of the $4 ; 1$ detected 1, 8 detected 2, and 5 detected 3 . Sour was the least identified and sweet the most easily identified of the taste modalities.

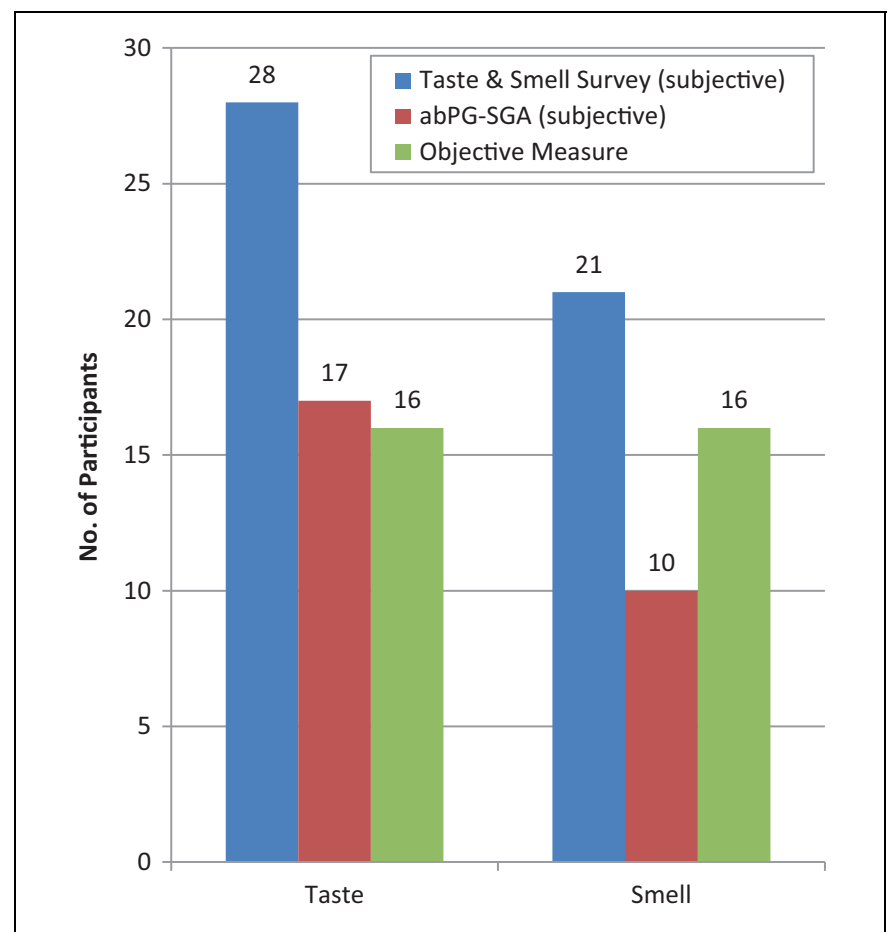

Figure 3. Prevalence of subjective versus objective measures of taste and smell abnormalities.

Seven reported certain foods (eg, coffee, fried foods, pasta, and stuffing) smelled different since becoming ill. Objective tests found 16 had ISP. In contrast, only 10 reported subjective smells as weaker/could not smell and a further 5 said smells were stronger. Objective tests did not allow increased acuity to be tested.

\section{Taste and Smell Abnormality Severity}

Subjective chemosensory complaint scores are presented in Figure 5. The median taste complaint score $=4.5$ (range 0-9) and the median smell score $=2$ (range $0-4)$. The combined chemosensory complaint score $=7$ (range $0-11)$. The severity of subjective TC $(\mathrm{n}=28)$ were insignificant $(\mathrm{n}=3)$, mild $(\mathrm{n}=$ $8)$, moderate $(n=9)$, severe $(n=5)$, and incapacitating $(n=3)$. Subjective SC $(\mathrm{n}=22)$ were insignificant $(6)$, mild $(\mathrm{n}=8)$, moderate $(\mathrm{n}=7)$, and incapacitating $(\mathrm{n}=1)$.

\section{Taste and Smell Abnormalities and Quality of Life}

Of those with a TSA, almost half $(n=13 / 28)$ reported that QoL was affected. Eleven of these had subjective TC $(n=11 / 13)$, while 5 had objective ITP $(n=5 / 13)$. Only 4 with SC and 3 with ISP reported reduced QoL.

\section{Nutritional Status and NIS}

Ninety-six per cent with TSA $(n=27 / 28)$ had an abPG-SGA score $\geq 6$, which indicated malnutrition risk. The median abPG SGA score (for those with a full data set and at least one TSA; 


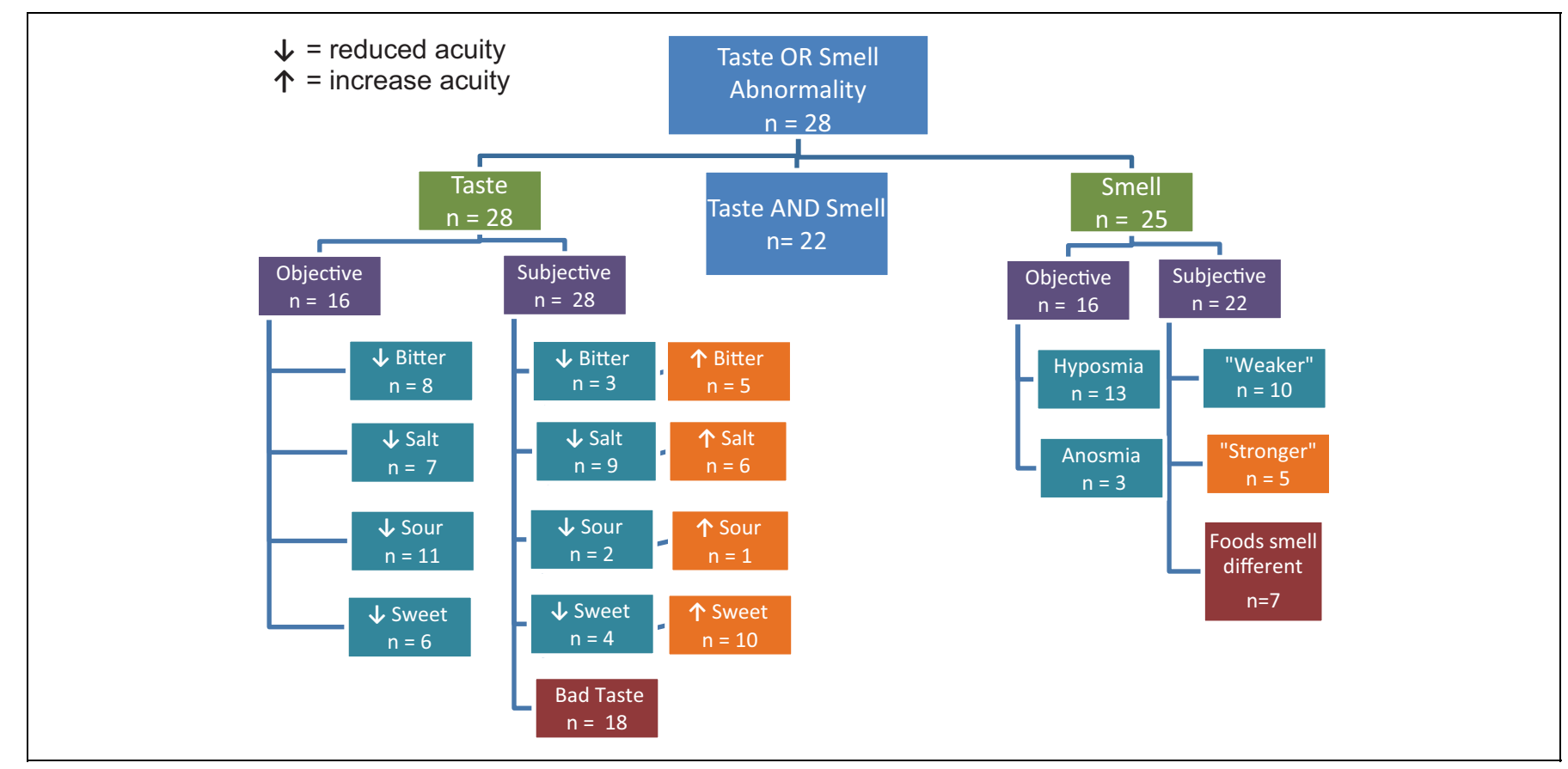

Figure 4. Characteristics of subjective and objective taste and smell abnormalities $(N=30)$.

$\mathrm{n}=25$ ) was $13 / 36$ (range: $4-27$ ). Body mass index $(\mathrm{BMI})^{28}$ could not be calculated for 3 participants due to missing data. The 2 without TSA were also at malnutrition risk.

Twenty $(20 / 27 ; 74 \%)$ had normal or above normal BMI. All 7 underweight patients had TSA. In those with TSA and malnutrition risk $(\mathrm{n}=27) 12$ lost weight, 10 gained weight, and 3 were weight stable in the prior 6 months. Most with TSA reported eating "less than usual" during the previous 2 weeks $(\mathrm{n}=17 / 28)$. The majority $(\mathrm{n}=12 / 17)$ ate "normal foods but less than normal amounts." The rest reported eating "little solid food." NIS were reported by $96 \%(n=27 /$ 28 ) with TSA (Figure 6). The median number of NIS reported was 6.5/14, (range: 0-13). The regression model showed a nonsignificant relationship $(P=.585)$ between TSA and malnutrition scores.

\section{Discussion}

Combined subjective and objective assessment yielded high TSA prevalence, but this varied with assessment method. Many reported subjective TC and SC, but without objective abnormality. Persistent bad taste was the most common abnormality. Changes in how food tasted and smelled, and increases and/or decreases in taste and/or smell perception were frequent.

No previous studies have combined subjective and objective tools to assess taste and smell in advanced cancer. The characteristics of TSA varied depending on assessment method and these variations challenge our understanding of the etiology and pathophysiology of TSA.

This advanced cancer study population had mostly solid tumors, poor performance status, and a representative age profile. TSA sometimes occurred together, but in other instances TC and/or ITP were present when smell was normal and vice versa. Participants seemed less aware of SC, and so it was not surprising that TC were more common and perceived as more severe than SC. The discrepancy in TSA prevalence between TSS and abPG-SGA may relate to the variation in time frame; the abPG-SGA captures symptoms in the 2 weeks prior to assessment, but the TSS captures any change in taste or smell since diagnosis.

Malnutrition risk was high despite mostly normal BMI. NIS were common and frequently co-occurred. A common theme, in our study and the work of others, ${ }^{29,30}$ was that food lacked taste or was bland. This interfered with food enjoyment, most notably main meals and eating out.

Our TSA prevalence at $93 \%$ was higher than other studies in advanced cancer (50\%-90\%). ${ }^{3,14}$ This may reflect the fact that unlike other studies, both taste and smell were assessed with both objective and subjective measures.

Objective ITP and ISP were recorded in equal measure, but did not co-occur in all TSA participants. Subjective TC were more common than SC. This supports the findings of others who used TSS. ${ }^{1,2}$ Another study ${ }^{31}$ also observed lower SC awareness using a different assessment. This may explain why in our study subjective TC were considered more severe and had a higher QoL impact than SC, ITP, or ISP. Contrary to other work ${ }^{1,2}$ in advanced cancer, the impact of TSA on QoL was relatively low overall.

Altered taste and smell were found by both subjective and objective measures. Subjective TC were most common for "salt" (mostly weaker) and "sweet" (mostly stronger). This supports similar subjective findings in treatment-naïve patients 

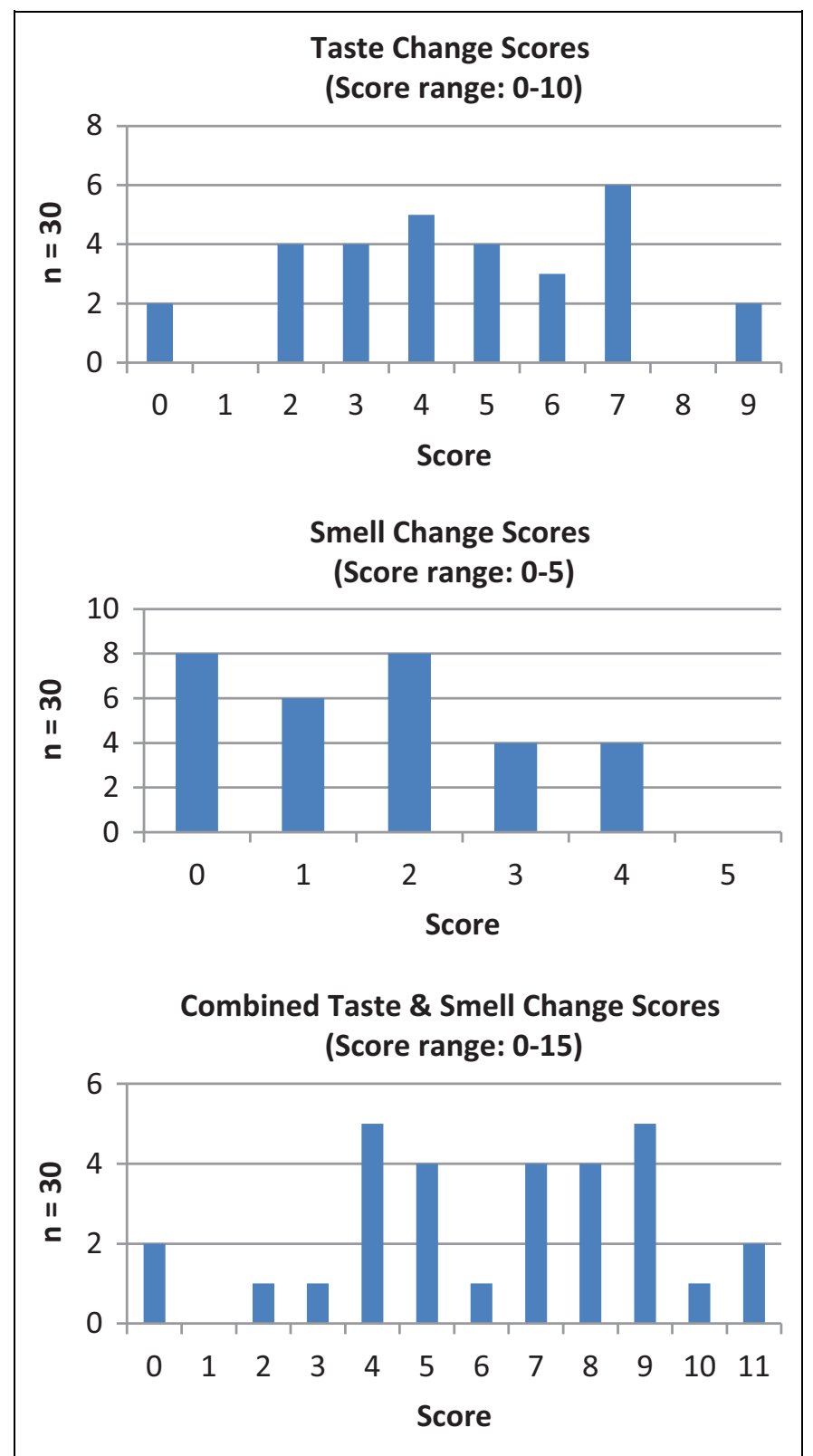

Figure 5. Subjective chemosensory complaint scores.

with cancer. ${ }^{11}$ Stronger "sweet" taste intensity has been reported during chemotherapy ${ }^{9,10}$ while other advanced cancer studies noted both increased and decreased "salt" sensitivity ${ }^{1}$ and decreased "sweet" sensitivity., 3,29

Despite fewer reported subjective TC for "bitter" and "sour," objective ITP was most frequent for these modalities. Others ${ }^{29}$ also documented poor "bitter" detection in a similar cohort, with different objective measures. Some investigators ${ }^{1}$ found increased "bitter" and "sour" sensitivity on the TSS; we did not. In a similar cohort, "stronger" taste acuity was more common than "weaker" for all taste modalities. ${ }^{2}$ Eighty three per cent of participants had SC and/or ISP. This exceeded previously reported prevalence of $60 \%{ }^{31}$
Smells were most commonly weaker. Evidence from others suggests TSA can impact weight loss and nutritional status, ${ }^{1,2,10,15}$ but we did not identify any association.

This study had several limitations. A small sample size and high TSA prevalence limited statistical power. A larger sample size would help determine associations between TSA, NIS and malnutrition risk across different cancer types. The study population was predominantly female. This may have impacted results as women are thought more sensitive to taste and smell than men. ${ }^{23,32}$ The assessment tools employed were used in previous TSA cancer studies, ${ }^{1,9,12,20,21}$ facilitating comparison of results. Despite a literature search, no validated subjective TSA assessment tool was identified. ${ }^{13}$ The TSS was interviewer-assisted by a single researcher to maximize item response rate.

Confusion about terminology and recognition of specific tastes was a methodological challenge. In particular, the taste descriptors "sour" and "bitter" were problematic. Some participants detected and recognized the taste, but failed to correctly label it. Others did not understand it. This may have interfered with the integrity of the TSS and the taste strips results. The struggle to articulate taste and smell experiences may be compounded by the fact that clinicians seldom enquire about TSA. ${ }^{33}$ Similar concerns were noted in the "Sniffin' Sticks" test as some of the smell options were unfamiliar. The "bitter" taste strip was always presented last, and this may have made it more susceptible to guess work. With objective tests only normal or reduced perception was detected. Increased perception was not captured. This may explain why subjective prevalence was higher than objective.

The high prevalence of TSA, malnutrition risk and NIS is clinically relevant in advanced cancer given that symptom management is central to palliative care. The use of TSA and malnutrition screening tools with common terminology could, over time, educate patients about the importance of TSA and common NIS and their impact on food enjoyment. Persistent bad taste is a significant common problem. Consideration should be given to devising simple, effective strategies to manage this symptom in advanced cancer. In order to fully understand the natural history of TSA, future studies should combine subjective and objective assessment in a longitudinal study from diagnosis to survivorship or end of life. We did not examine food intake. Quantitative dietary assessment should be considered in future studies to gain greater insight into the impact of TSA on food consumption, dietary patterns and malnutrition risk. Future studies should include matched healthy volunteers as a control group and time since treatment completion should be documented to better understand treatment effects. We used a modified version of the TSS; the current scoring system does not adequately differentiate TSA severity. We suggest a more comprehensive scoring system to better determine severity should be considered. Taste and smell survey validation is needed and may move us closer to a TSA assessment gold standard and facilitate earlier detection and management strategies. 


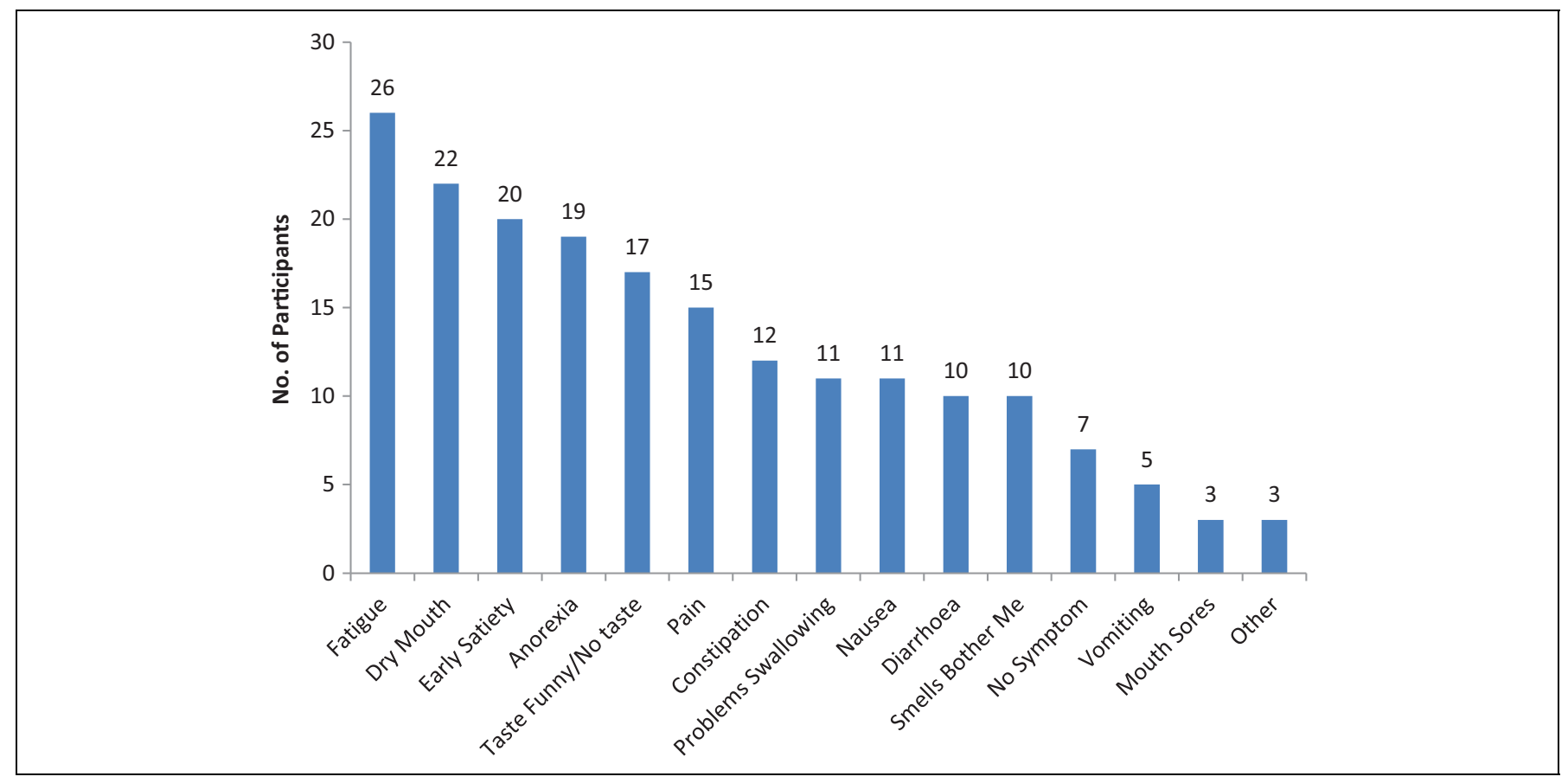

Figure 6. The prevalence of nutrition impact symptoms.

\section{Conclusion}

The prevalence of TSA in this advanced cancer cohort was high. Those with subjective TC and/or SC did not necessarily have objective ITP and/or ISP. This suggests that both assessments are needed for comprehensive evaluation. TSA abnormality characteristics varied, indicating a need for individualized assessment and management. Persistent bad taste was the most common complaint. Changes in taste perception were common with "salty" predominantly weaker and "sweet" mostly stronger. Over half were unable to correctly identify all 4 taste modalities and a similar number reported that particular foods tasted different and were not enjoyed as before. Smell perception was most commonly reported as weaker. Taste abnormalities were more severe than smell and had a greater impact on food enjoyment and QoL. Almost all participants were at malnutrition risk. All except one had NIS and most had multiple symptoms. No previous study combined the use of subjective and objective measures for both taste and smell assessment in advanced cancer. Our results contribute to the current, limited evidence-base in this field. Taste and smell abnormalities are a common problem in a heterogeneous advanced cancer population in hospice care.

\section{Declaration of Conflicting Interests}

The authors declared no potential conflicts of interest with respect to the research, authorship, and/or publication of this article.

\section{Funding}

The authors received no financial support for the research, authorship, and/or publication of this article.

\section{References}

1. Hutton JL, Baracos VE, Wismer WV. Chemosensory dysfunction is a primary factor in the evolution of declining nutritional status and quality of life in patients with advanced cancer. J Pain Symptom Manage. 2007;33(2):156-165.

2. Brisbois TD, de Kock IH, Watanabe SM, Baracos VE, Wismer WV. Characterization of chemosensory alterations in advanced cancer reveals specific chemosensory phenotypes impacting dietary intake and quality of life. J Pain Symptom Manage. 2011; 41(4):673-683.

3. Heckel M, Stiel S, Ostgathe C. Smell and taste in palliative care: a systematic analysis of literature. Eur Arch Otorhinolaryngol. 2015;272(2):279-288.

4. Gandhi AK, Roy S, Thakar A, Sharma A, Mohanti BK. Symptom burden and quality of life in advanced head and neck cancer patients: AIIMS study of 100 patients. Indian J Palliat Care. 2014;20(3):189-193.

5. Kirkova J, Walsh D, Rybicki L, et al. Symptom severity and distress in advanced cancer. Palliat Med. 2010;24(3):330-339.

6. Epstein JB, Smutzer G, Doty RL. Understanding the impact of taste changes in oncology care. Support Care Cancer. 2016;24(4): 1917-1931.

7. Wrobel BB, Leopold DA. Clinical assessment of patients with taste and smell disorder. Otolaryngol Clin North Am. 2004; 37(6):1127-1142.

8. Stinton N, Ali Atif M, Barkat N, et al. Influence of smell loss on taste function. Behav Neurosci. 2010;124(2):256-264.

9. Nishijima S, Yanase T, Tsuneki I, Tamura M, Kurabayashi T. Examination of the taste disorder associated with gynecological cancer chemotherapy. Gynecol Oncol. 2013;131(3):674-678. 
10. Sanchez-Lara K, Sosa-Sanchez R, Green-Renner D, et al. Influence of taste disorders on dietary behaviors in cancer patients under chemotherapy. Nutr J. 2010;9:15.

11. Imai H, Soeda H, Komine K, Otsuka K, Shibata H. Preliminary estimation of the prevalence of chemotherapy-induced dysgeusia in Japanese patients with cancer. BMC Palliat Care. 2013; 12(1):38.

12. Spotten L, Corish C, Lorton C, et al. Subjective taste and smell changes in treatment-naive people with solid tumours. Support Care Cancer. 2016;24(7):3201-3208.

13. Spotten LE, Corish CA, Lorton CM, et al. Subjective and objective taste and smell changes in cancer. Ann Oncol. 2017;28(5): 969-984.

14. Schalk P, Kohl M, Herrmann HJ, et al. Influence of cancer and acute inflammatory disease on taste perception: a clinical pilot study. Supportive Care Cancer. 2018;26(3): 843-851.

15. Brisbois TD, Hutton JL, Baracos VE, Wismer WV. Taste and smell abnormalities as an independent cause of failure of food intake in patients with advanced cancer-an argument for the application of sensory science. J Palliat Care. 2006;22(2): 111-114.

16. Boltong A, Aranda S, Keast R, et al. A prospective cohort study of the effects of adjuvant breast cancer chemotherapy on taste function, food liking, appetite and associated nutritional outcomes. Plos One. 2014;9(7):e103512.

17. Hong JH, Omur-Ozbek P, Stanek BT, et al. Taste and odor abnormalities in cancer patients. J Support Oncol. 2009;7(2): 58-65.

18. Oken MM, Creech RH, Tormey DC, et al. Toxicity and response criteria of the Eastern cooperative oncology group. Am J Clin Oncol. 1982;5(6):649-655.

19. Heald AE, Pieper CF, Schiffman SS. Taste and smell complaints in HIV-infected patients. AIDS. 1998;12(13):1667-1674.

20. McGreevy J, Orrevall Y, Belqaid K, et al. Characteristics of taste and smell alterations reported by patients after starting treatment for lung cancer. Support Care Cancer. 2014;22(10): 2635-2644.

21. Belqaid K, Orrevall Y, McGreevy J, et al. Self-reported taste and smell alterations in patients under investigation for lung cancer. Acta Oncol. 2014;53(10):1405-1412.
22. Bernhardson BM, Olson K, Baracos VE, Wismer WV. Reframing eating during chemotherapy in cancer patients with chemosensory alterations. Eur J Oncol Nurs. 2012;16(5):483-490.

23. Landis BN, Welge-Luessen A, Bramerson A, et al. "Taste Strips" - a rapid, lateralized, gustatory bedside identification test based on impregnated filter papers. J Neurol. 2009;256(2):242-248.

24. Hummel T, Kobal G, Gudziol H, Mackay-Sim A. Normative data for the "Sniffin' Sticks" including tests of odor identification, odor discrimination, and olfactory thresholds: an upgrade based on a group of more than 3,000 subjects. Eur Arch Otorhinolaryngol. 2007;264(3):237-243.

25. Fjaeldstad A, Kjaergaard T, Van Hartevelt TJ, et al. Olfactory screening: validation of Sniffin' Sticks in Denmark. Clin Otolaryngol. 2015;40(6):545-550.

26. Ottery FD. Definition of standardized nutritional assessment and interventional pathways in oncology. Nutrition. 1996;12(suppl 1): S15-S19.

27. Gabrielson DK, Scaffidi D, Leung E, et al. Use of an abridged scored patient-generated subjective global assessment (abPGSGA) as a nutritional screening tool for cancer patients in an outpatient setting. Nutr Cancer. 2013;65(2):234-239.

28. World Health Organisation. Obesity: preventing and managing the global epidemic: report of a WHO consultation. Geneva 2000. http://www.who.int/iris/handle/10665/42330. Accessed 18th February 2019.

29. Mahmoud FA, Aktas A, Walsh D, Hullihen B. A pilot study of taste changes among hospice inpatients with advanced cancer. $\mathrm{Am}$ J Hosp Palliat Care. 2011;28(7):487-492.

30. Bernhardson B-M, Tishelman C, Rutqvist LE. Chemosensory changes experienced by patients undergoing cancer chemotherapy: a qualitative interview study. J Pain Symptom Manage. 2007;34(4):403-412.

31. Yakirevitch A, Bercovici M, Migirov L, et al. Olfactory function in oncologic hospice patients. J Palliat Med. 2006;9(1):57-60.

32. Yakirevitch A, Bercovici M, Talmi YP. Olfaction in palliative care patients. In: Preedy VR, ed. Diet and Nutrition in Palliative Care. Boca Raton, FL: CRC Press; 2011:223-229.

33. Ponticelli E, Clari M, Frigerio S, et al. Dysgeusia and healthrelated quality of life of cancer patients receiving chemotherapy: a cross-sectional study. Eur J Cancer Care (Engl). 2017;26(2). 